\title{
Patents to Exclude vs. Include: Rethinking the Management of Intellectual Property Rights in a Knowledge-Based Economy
}

\author{
Patrick Cohendet and Julien Pénin
}

\author{
"[Patents] are, in the conditions of the perennial gale, incidents, often" \\ unavoidable incidents, of a long-run process of expansion which they \\ protect rather than impede. There is no more of paradox in this than \\ there is in saying that motorcars are traveling faster than they \\ otherwise would because they are provided with brakes.
}

Joseph Schumpeter (1883-1950)

Economist and Political Scientist

\begin{abstract}
Traditional patent theory emphasizes the importance of patents for excluding imitators. This view is far too restrictive and is at odds with many empirical and theoretical works. Therefore, we propose an analysis of patent management that considers the properties of knowledge-based economies explicitly. Patents are thus shown to be critical instruments for coordinating innovative activities between firms. They not only exclude potential infringers, but also "include" all the heterogeneous stakeholders of the innovation process. Patents facilitate coordination via two mechanisms: they encourage the emergence of markets for technology (market coordination) and they play an important role in formal and informal inter-firm collaboration (non-market coordination). We also link firms' patenting strategy with the characteristics of the technological regime of their sector.
\end{abstract}

\section{Introduction}

The traditional economic framework considers invention as an individual, isolated act and therefore emphasizes the importance of patents to exclude imitators and preserve individual incentives to invent (Arrow, 1962; http://tinyurl.com/7n4rg2y). However, this view is far too restrictive and runs counter to most of the empirical and theoretical research conducted in the past three decades (Levin et al., 1987: http://tinyurl.com/mwwegm; Cohen et al., 2000: http://tinyurl.com/8ynxuzw).

Empirical studies unanimously suggest that firms do not consider patents to be efficient devices for excluding infringers and protecting inventions. Nonetheless, more and more patents are issued each year. It is therefore paradoxical that the more firms criticize the efficiency of patents as tools of exclusion, the more they apply for patents (Kortum and Lerner, 1999: http://tinyurl .com/7x99zjz; Bessen et al., 2007: http://tinyurl.com/7lsh8p6).

The only way to escape this paradox is to shift the focus from the traditional economic framework and embrace a wider framework that would consider the properties of knowledge and innovation more explicitly. This new framework specifies a dual role for patents: patents can increase incentives to innovate but they can also mitigate the specific coordination difficulties linked to open innovation (Chesbrough, 2003; http://tinyurl.com/ce6bsy8). According to the principles of open innovation, it is fundamental for firms to exchange knowledge and technologies and to collaborate formally and informally. However, this exchange and interaction process is complicated by the properties of knowledge (its tacit dimension, for instance) and by the existence of information asymmetries. In other words, a firm willing to develop an open innovation strategy is likely to encounter problems in the search for partners and the exchange of knowledge and technologies. The patent system can help solve those coordination problems. We show that, according to the context, the main role of the patent system is not to effectively exclude rivals but to "include" all the stakeholders in the innovation process.

The remainder of the paper is organized as follows. We first discuss the role of coordination of patents; in particular, we distinguish market and non-market coordination. Next, we provide an analytical framework to 


\section{Patents to Exclude vs. Include: Rethinking the Management of IPR}

\section{Patrick Cohendet and Julien Pénin}

explain when patents should be used primarily to rather include than exclude. We conclude by suggesting avenues of future research.

\section{Patents as Instruments of Coordination}

Patents facilitate interactions among actors in the innovation process because they hold two important properties concurrently: they both protect and disclose an invention. The coupling of these two properties allows patents to ease interactions among innovators at two levels: first, they facilitate technology transfer through the exchange of licenses on markets for technology (market coordination) and second, they play a key role in framing collaborations and alliances (formal and informal) among heterogeneous organizations (nonmarket coordination).

Market coordination: patents to favour technology trading Patents help technology and knowledge trading on markets for technology (Arora et al., 2001: http://tinyurl.com/ cj8kwrq; Arora and Gambardella, 2010: http://tinyurl.com/ 7vdzqrm) (Box 1). The combination of the two properties of protection and knowledge disclosure notably favours indeed sustained market trading of technologies. The disclosure of knowledge allows technology sellers to signal and to advertise their products, whereas the protection granted by the patent system also prevents buyers from free riding. In other words, the patent system softens Arrow's paradox (1962), thus favouring the transfer of both codified and tacit knowledge in markets for technology.

By supporting the formation of markets for technology, patents induce the development of a new type of firm specialized in knowledge production (Arora and Merges, 2004; http://tinyurl.com/6qebd73). One of the main assertions of classical economic theory is that markets entail division of labour and vertical specialization. Thus, markets for technology support the emergence of fabless firms (or technological firms) that work upstream in the production of new technology that they then transfer to manufacturing firms, located downstream on the value chain. The latter use those technologies in their products. This new industrial organization has major positive normative implications: it facilitates the division of labour and allows each firm to specialize where it is most efficient. It also enhances the distribution of technologies, which ensures that innovations are used by those that can generate the most value from them. Finally, it prevents costly duplication of research.

\section{Box 1. Markets for Technology}

Even in presence of patents, the emergence of markets for technology is not straightforward because there are still major obstacles to such markets (Teece, 1986; http://tinyurl.com/7s43qsg). To respond to a need for lower transaction costs on technology markets, new actors have recently emerged - such as Innocentive (http://innocentive.com), Yet2.com (http://yet2.com), and Ocean Tomo (http://oceantomo.com) - often assisted by new information and communication technologies. The role of those patent brokers is to organize and facilitate exchanges between technology sellers and buyers. To do so, they provide technical assistance, audit, and perform diagnostic tests to assess the value of a given technology. Most importantly, they facilitate the circulation of information (Yanagisawa and Guellec, 2009: http://tinyurl.com/7usbboy; Dushnitsky and Klueter, 2011; http://tinyurl.com/7g4fvat).

Patents are not always exchanged for money. They can also be used to barter for other patents (within cross-licensing agreements). Patents are often used defensively as bargaining chips to protect their holders from uncertain and risky lawsuits and to acquire the right to use specific technologies, thus preserving the freedom to operate (Grindley and Teece, 1997: http://tinyurl.com/ ccso2v3; Rivette and Kline, 2000: http://tinyurl.com/bv4lcr6). For instance, in complex technological sectors, innovation typically combines several technologies. Its implementation often requires the combination of several overlapping patents. In such a case it is likely that the patent held by one individual infringes several other patents, and vice versa (thus, freedom to exclude and freedom to use do not converge). Anticipating such situations, firms are induced to gather large patent portfolios that serve as "legal bargaining chips" (Hall and Ziedonis, 2001; http://tinyurl.com/7bzmqvt).

\section{Non-market coordination: patents to collaborate and form alliances}

Even more than as a defensive tool aimed at protecting its holder against legal attacks or negotiating better licensing agreements, patents can be used in an explicitly cooperative manner. For isolated actors who need to collaborate, a patent can be a way to signal the abilities of the holder and to negotiate partnership agreements. In this case, patents intervene fairly early in the 


\section{Patents to Exclude vs. Include: Rethinking the Management of IPR}

\section{Patrick Cohendet and Julien Pénin}

innovation process and their role goes beyond merely allocating existing resources. They help to structure formal or informal collective modes of knowledge creation (networks, research consortium, research joint venture, informal exchanges, etc.). A patent can be of use during several steps in the collaboration process between different organizations.

First, as stated before, in the early stages of collaboration, patents can allow actors to signal their competencies, thus mitigating the problems of incomplete information and facilitating the search for a partner. They also tend to reduce the risks linked to cooperation caused by free riding by one of the partners (Ordover, 1991; http://tinyurl.com/85lr829), therefore increasing the incentives to participate in the venture. Patents can also play a key role when determining the terms of the collaboration. They allow the skills of each partner to be assessed (i.e., they provide a benchmark that enables firms to compare their relative strengths). Without patents, firms would find it more difficult to evaluate their relative abilities and consequently to agree on the terms of the collaboration. Patents also allow firms to enforce their claims because they represent a credible threat that could block an agreement. In this sense, patents are central devices in determining the bargaining power of each party. After the collaboration, patents may also be used as instruments for sharing the outcome of the collaboration, through a joint application, for instance (Hagedoorn, 2003; http://tinyurl.com/725zu6c).

A peculiar case of the use of patents to foster collaboration is when a firm uses the patent system to release a technology free of charge (or at almost no cost). In such cases, firms use patents not to exclude imitators but to foster the large-scale distribution and use of the technology. An example of this sort of open-patent strategy can be seen in network industries when firms seek to benefit from network effects of standard implementation. In this case it is most important for firms to distribute their technology widely, which may require releasing it for almost free (Corbel, 2003; http://tinyurl .com/7vfjnmr). Here, firms use patents to try to impose the use of their own technology rather than to prevent its use. (Note: This is in contrast with scientific publication, which might also lead to broad dissemination of the technology but at a lower cost. A patent has the advantage of allowing control of improvements.) Another example of this peculiar use of the patent system lies in open-source utilization of intellectual property. It is indeed possible to use the patent system in a copyleft way (i.e., not to exclude but to prevent exclusion and to secure open access to the knowledge base) (Pénin and Wack, 2008; http://tinyurl.com/826npmq).

To conclude, reconsidering the properties of the innovation process entails rethinking the role of patents. In parallel to their traditional role as tools of exclusion an equally important second role is emerging: to coordinate actors in the innovation process. Initially construed as being designed to reward the independent innovator, industrial property is consequently viewed as a structuring element of open innovation, to use the now-famous terminology of Chesbrough (2003; http://tinyurl.com/ce6bsy8).

\section{An (Exploratory) Analytical Framework for Understanding the Diverse Roles of Patents}

Because a patent is a flexible instrument that can be used either to exclude or to include, choosing the optimal patenting strategy for the firm is a central issue. When should firms rely on exclusive strategies versus more collaborative ones? This choice is largely influenced by the technological regime of the sector (Nelson and Winter, 1982; http://tinyurl.com/7mf2v7s). Obviously, the nature of the firm (its size, experience, etc.) and the nature of the competitive regime might also influence the patenting strategy. For instance, small firms are less able to rely on exclusive strategies because they need to collaborate with holders of complementary assets. Nonetheless, those conditions matter less than the nature of the technology. Table 1 summarizes the effect of the technological regime's characteristics on firms' optimal patenting strategies.

The tacit versus codified nature of the knowledge base The more codified the knowledge, the easier it is to exchange it voluntarily (via market arm's length transactions) or involuntarily (via spillovers) (Teece, 1986; http://tinyurl.com/7s43qsg). Therefore, when the knowledge base is highly codified, firms mostly tend to use patents in the traditional way either to exclude competitors and to secure a monopoly position on their product market, or to trade their invention on technology markets. Conversely, the more tacit the underlying knowledge, the more difficult it is to transfer and exchange, and therefore the more firms will be tempted to use patents to foster collaboration with suppliers, rivals, etc.

\section{Emerging versus stabilized situations}

This distinction encompasses the tacit vs. codified dimension discussed above but cannot be limited to it. 


\section{Patents to Exclude vs. Include: Rethinking the Management of IPR}

\section{Patrick Cohendet and Julien Pénin}

Table 1. The influence of the technological regime on the optimal patenting strategy

\begin{tabular}{|c|c|}
\hline $\begin{array}{l}\text { Characteristics of } \\
\text { technological regime* }\end{array}$ & Impact on patenting strategy \\
\hline Tacit knowledge base & $\begin{array}{l}\text { Makes imitation and communication harder } \\
\text { Favours the non-market coordination role of patents }\end{array}$ \\
\hline Codified knowledge base & $\begin{array}{l}\text { Facilitates imitation and technology exchanges } \\
\text { Favours an exclusive role or a market coordination of } \\
\text { patents }\end{array}$ \\
\hline $\begin{array}{l}\text { Emerging (versus stabilized) } \\
\text { technology }\end{array}$ & $\begin{array}{l}\text { Increases the need to build shared codes and } \\
\text { common knowledge base } \\
\text { Favours the coordination role of patents }\end{array}$ \\
\hline $\begin{array}{l}\text { Complex (versus simple) } \\
\text { technology }\end{array}$ & $\begin{array}{l}\text { Reduces the freedom to operate } \\
\text { Favours a defensive use of patents }\end{array}$ \\
\hline $\begin{array}{l}\text { Modular (versus integrated) } \\
\text { technology }\end{array}$ & $\begin{array}{l}\text { Increases the division of labour of inventive work } \\
\text { Favours the coordination role of patents }\end{array}$ \\
\hline Existence of network effects & $\begin{array}{l}\text { Increases the gains linked to the diffusion of the } \\
\text { technology } \\
\text { Favours an open and non-exclusive use of patents }\end{array}$ \\
\hline
\end{tabular}

*Note: The characteristics in this table are not ordered by importance. The effect of each characteristic must be interpreted ceteris paribus.

Winter (1993; http://tinyurl.com/6rntnzz) underlined the fact that aggressive use of patents may generate inefficiencies during the first phases of the innovation process, when a pool of innovators explores a new trajectory. Winter's argument referred to an important issue that has been widely neglected to date, and which deals with the distinction between emerging and stabilized phases of innovation introduced by Callon (1999; http://tinyurl.com/7zjyj79). For Callon, it is important to distinguish two phases within the innovation process: an emerging phase, during which knowledge is mostly tacit and uncertainty at all levels prevails, and a stabilized phase, during which knowledge has been codified and market and technology perspectives are clearer. Within such a framework it is apparent that the aggressive use of patents to exclude rivals occurs mostly in stabilized phases. Conversely, in emerging phases, the need to build a common knowledge base is strong and therefore collaboration strategies tend to supersede strategies of exclusion. Thus, the primary aim of actors is to collaborate and to find partners, which induces them to use patents accordingly. However, as innovations become more mature and situations are stabilized, the importance of patents as instruments of exclusion increases.

The simple versus complex nature of the technology base This dimension fundamentally affects firms' patenting strategy because it deals with the freedom that patent holders have in the use of their patent rights. The distinction between complex and simple technologies is linked to the difference between the right to exclude infringers, which is the right given by a patent, and the right to use a technology. When a technology is simple (mono-component) those two rights converge. In other words, the patent holder has the right to use the patented invention (this use does not infringe other patents). (An example of a simple technology can be found in chemical-based technologies. A molecule, for instance, is usually protected by one single patent. A pharmaceutical company that has a patent on a molecule can therefore exclude infringers and use its monopoly power 


\section{Patents to Exclude vs. Include: Rethinking the Management of IPR}

\section{Patrick Cohendet and Julien Pénin}

over the medicines based upon the protected molecules. Rivals can thus be excluded.) When a technology is complex (multi-component), however, it is possible (and sometimes likely) that those two rights do not correspond (i.e., a patent holder cannot use his invention because by using it, it infringes patents held by other firms.) Hence, complex and simple technologies induce very different strategic behaviours with respect to patents (Grindley and Teece, 1997; http://tinyurl.com/ ccso2v3). As Kingston (2001; http://tinyurl.com/czhllg7) asserts, in complex sectors, firms tend to use patents defensively (to secure operating freedom) while in simple sectors, they tend to use patents offensively (to exclude imitators).

\section{The existence of network effects}

Network industries are characterized by specific patenting strategies. Given that the value of the good increases with the number of users, it is critical in those industries to achieve compatibility and to implement a standard, ideally a unique one (Cusumano and Gawer, 2002; http://tinyurl.com/cze2tdo). However, to implement a standard, firms must provide open access to their technologies. Secrecy and exclusive behaviours are inefficient strategies if the goal is to ensure compatibility. Hence, in network industries, patent holders have strong incentives to use their patent in an open, non-exclusive way to foster the adoption of their invention and to increase its chances of becoming the industry standard (Corbel, 2003; http://tinyurl.com/7vfjnmr).

\section{The modular versus integrated nature of technology}

Linked to the former point, the modular nature of a technology also affects the optimal patenting strategy. Basically, when a technology is highly modular, actors in the innovation process benefit greatly from maximally decentralizing the production process to derive the specialization gains that arise from the division of labour (Brusoni and Prencipe, 2001; http://tinyurl.com/ coapzg7). In those cases, where firms are highly interdependent, compatibility issues are again prevalent and firms might have strong incentives not to use their patent portfolio to exclude but rather to coordinate this collective innovation process. The case of genetically engineered vaccines analyzed by Bureth and Pénin (2007; http://tinyurl.com/ctest7p) is particularly illuminating.

\section{Conclusion}

This work proposed a new framework for understanding the way firms manage their patent portfolio in a knowledge-based economy. A patent is not a tool dedic- ated solely to the exclusion of potential imitators. It is also used to facilitate coordination and interaction among the actors in an industry. This point has been emphasised by many authors in the field of innovation and knowledge (Teece, 1986: http://tinyurl.com/7s43qsg; Mazzoleni and Nelson, 1998: http://tinyurl.com/bml2pbk; Jaffe, 2000: http://tinyurl.com/cj9y6ej; Chesbrough, 2003: http://tinyurl.com/ce6bsy8) but has largely been underestimated in the "traditional" economic and managerial literature.

Our analysis, although it will need to be improved upon, provides insight into the main differences in patenting behaviours across industries. Pharmaceuticals, electronics, software, networks, and aeronautics all rely on very different technological regimes, which largely explains their disparate patenting strategies.

This view of patents as an instrument central to resolving coordination problems in the early stages of the emergence of a technology has many implications for management sciences. Here are some "hot spots" on which our work may shed new light: first, firms must adapt their intellectual property strategy to their business context. A winning strategy in one specific context (a strategy of exclusion, for example, to protect the market of a blockbuster drug) may have disastrous consequences in another context (the birth of a new technology). Second, because contexts may change, firms must be willing to re-evaluate their intellectual property strategy from time to time. In particular, a strategy of coordination that has been successful in emerging phases may have to be changed to a strategy of exclusion as the situation becomes more stable. Third, practitioners who want to develop open innovation strategies must not neglect the issue of intellectual property are a central element of such a strategy. Open innovation does not mean innovation without patents; on the contrary (Laursen and Salter, 2006: http://tinyurl.com/ct9t9wo; West, 2006: http://tinyurl.com/cfgvgk; Lichtenthaler, 2010: http://tinyurl.com/d9kwoc2).

Finally, from a policy-maker perspective, our view of patents leads to prefer a US patent system with its oneyear grace period rather than a system without such grace period. The existence of a grace period enables inventors to signal their invention at an early phase, thus favouring interactions, exchanges, and a collective development of inventions while the European system, without such a grace period, induces inventors to preserve secrecy, thus impeding such a collective dynamics. 


\title{
Patents to Exclude vs. Include: Rethinking the Management of IPR
}

Patrick Cohendet and Julien Pénin

\begin{abstract}
About the Authors
Patrick Cohendet is Professor of Economics at HEC Montréal business school in Canada. He was previously a professor at the University of Strasbourg, France. His research interests include the economics of innovation, technology management, knowledge management, theory of the firm, and the economics of creativity. He is the author or co-author of 15 books and over 60 articles in refereed journals. He has conducted a series of economic studies on innovation and economics of knowledge (measurement of spin-offs, evaluation of the economic benefits of $R \& D$ projects, evaluation of technology transfer, etc.). These studies were carried out by his research laboratory BETA of the University of Strasbourg, and MOSAIC at HEC Montreal for different European and North American organisations such as the European Commission, the EU, OECD, Council of Europe, and the Canadian Space Agency.

Julien Pénin is Associate Professor at the University of Strasbourg, France, and is a researcher at BETA (Bureau d'Economie Théorique et Appliquée). His research interests include economics and management of patents, open innovation, and open source innovation. He has authored and coauthored over 20 articles in refereed journals. Julien also teaches economics and management of innovation and intellectual property rights at the department of economics and management of the University of Strasbourg.
\end{abstract}

